\title{
Geometrical Computer Vision from Chasles to Today
}

\author{
K. Åström \\ Centre For Mathematical Sciences, Lund University, Lund, Sweden \\ kalle@maths.lth.se
}

\begin{abstract}
In this talk I will present geometrical computer vision from its early beginnings in projective geometry and photogrammetry to new research on methods in algebraic geometry. In the talk I will give examples of theory for minimal structure and motion problems (central and non-central cameras, $1 \mathrm{D}$ and $2 \mathrm{D}$ retina), critical configurations and geometry in general as well as practical results of using such theory in $3 \mathrm{D}$ reconstruction, navigation, modelling and image interpretation.
\end{abstract}

\section{References}

1. K. Åström and F. Kahl. Motion estimation in image sequences using the deformation of apparent contours. IEEE Trans. Pattern Analysis and Machine Intelligence, 21(2):114-127, 1999.

2. K. Asström and F. Kahl. Ambiguous configurations for the 1d structure and motion problem. Journal of Mathematical Imaging and Vision, 18(2):191-203, 2003.

3. K. Åström and M. Oskarsson. Solutions and ambiguities of the structure and motion problem for 1d retinal vision. Journal of Mathematical Imaging and Vision, 12(2):121-135, 2000.

4. Rikard Berthilsson, Kalle Åström, and Anders Heyden. Reconstruction of curves in $r^{3}$ using factorization and bundle adjustment. Int. Journal of Computer Vision, 41(3):171-182, 2001.

5. T. Buchanan. Photogrammetry and projective geometry - an historical survey. SPIE, 1944:82-91, 1993.

6. M. Chasles. Question 296. Nouv. Ann. Math., 14(50), 1855.

7. A. Heyden. Reconstruction from image sequences by means of relative depths. Int. Journal of Computer Vision, 24(2):155-161, September 1997. also in Proc. of the 5th International Conference on Computer Vision, IEEE Computer Society Press, pp. 1058-1063.

8. E. Kruppa. Zur Ermittlung eines Objektes Zwei Perspektiven mit innerer Orientierung. Sitz-Ber. Akad. Wiss., Wien, math. naturw. Kl. Abt, IIa(122):1939-1948, 1913.

9. D. Nistér. An efficient solution to the five-point relative pose problem. In Proc. Conf. Computer Vision and Pattern Recognition, volume 2, pages 195-202. IEEE Computer Society Press, 2003.

10. D. Nistér and F. Schaffalitzky. What do four points in two calibrated images tell us about the epipoles? In Proc. 8th European Conf. on Computer Vision, Prague, Czech Republic, 2004. 
11. H Schubert. Die trilineare beziehung zwischen drei einstufigen grundgebilden. Mathematische Annalen, 17, 1880.

12. A. Shashua. Trilinearity in visual recognition by alignment. In Proc. 3rd European Conf. on Computer Vision, Stockholm, Sweden, pages 479-484, 1994.

13. P. Stefanovic. Relative orientation - a new appraoch. ITC Journal, 3:417-448, 1973.

14. H. Stewénius. Gröbner Basis Methods for Minimal Problems in Computer Vision. PhD thesis, Lund University, 2005.

15. H. Stewńius, F. Kahl, D. Nistér, and F. Schaffalitzky. A minimal solution for relative pose with unknown focal length. In Proc. Conf. Computer Vision and Pattern Recognition, San Diego, USA, 2005.

16. B. Triggs. Matching constraints and the joint image. In Proc. 5th Int. Conf. on Computer Vision, MIT, Boston, MA, pages 338-343, 1995.

17. B. Vijayakumar, D. Kriegman, and J. Ponce. Structure and motion of curved 3D objects from monocular silhouettes. In Proc. Conf. Computer Vision and Pattern Recognition, pages 327-334, 1996. 